\title{
Chinese patients with sporadic Hirschsprung's disease are predominantly represented by a single RET haplotype
}

\author{
M-M Garcia-Barceló, M-H Sham, V C-H Lui, B L-S Chen, Y-Q Song, W-S Lee, S-K Yung, G Romeo, \\ P K-H Tam
}

$\mathrm{H}$ irschsprung's disease is a developmental disorder characterised by the absence of ganglion cells in the nerve plexuses of the lower digestive tract. The Hirschsprung phenotype is variable and can be classified into two groups: SSA, or short segment aganglionosis, which includes patients with aganglionosis as far as the rectosigmoid junction; and LSA, or long segment aganglionosis, which includes patients with aganglionosis beyond the rectosigmoid junction. The condition presents in the neonatal period as a failure to pass meconium, chronic severe constipation, colonic distension, secondary electrolyte disturbances, and sometimes enterocolitis and bowel perforation.

The estimated population incidence is $1 / 5000$ live births, although this is a representative value. The highest incidence is in Asian populations (2.8 per 10000 life births) and the lowest in Hispanics ( 1 per 10000 life births). ${ }^{1}$ The male to female $(\mathrm{M}: \mathrm{F})$ ratio is approximately $4: 1$ for SSA patients and approximately 1:1 for LSA patients. ${ }^{1}$ Approximately $20 \%$ of cases are familial. The recurrence risks for siblings of SSA variant probands ranges between $1.5 \%$ and $3.3 \%$, while the risks for those of LSA variant probands varies from $2.9 \%$ to $17.6 \%{ }^{1}$ Hirschsprung's disease is often associated with chromosomal abnormalities, with other neurodevelopmental disorders such as Waardenburg syndrome type 4, and with a variety of additional isolated anomalies and syndromes. ${ }^{12}$

The disease has a complex genetic aetiology, and many studies indicate the receptor tyrosine kinase gene $(R E T)$ as the major susceptibility gene for Hirschsprung's disease. ${ }^{1-14}$ RET mutations are also associated with multiple endocrine neoplasia type 2 (MEN2), ${ }^{15}$ and medullary thyroid carcinoma. ${ }^{16}$ Papillary thyroid carcinoma is associated with RET somatic rearrangements. ${ }^{17}$

Mutations in the RET gene account for up to $50 \%$ of the familial cases and anywhere between $7 \%$ and 35\% of the sporadic cases, and they lack genotype-phenotype correlation. $^{5-14}$ Other Hirschsprung genes identified so far mainly code for protein members of interrelated signalling pathways involved in the development of enteric ganglia: RET, endothelin receptor B (EDNRB), ${ }^{18-24}$ and the transcriptional regulator SOX10 signalling pathways. ${ }^{25}{ }^{26}$ Mutations in the SIPI gene have been found to cause syndromic Hirschsprung's disease. ${ }^{27}$ These genes account for a small proportion of patients with this disorder (7\%). Approximately $50 \%$ of affected individuals do not have mutations in the Hirschsprung genes. ${ }^{1}$ However, genetic linkage analyses in both LSA and SSA variant families repeatedly implicate the $R E T$ gene as a major susceptibility locus, ${ }^{28}{ }^{29}$ even though the evidence of those linkage analyses is not reflected in the RET mutation status of many patients in whom RET coding region mutations were not found.

There are several possible explanations for the complex genetic aetiology of Hirschsprung's disease:

- mutations in as yet unidentified genes;

\section{Key points}

- Hirschprung's disease has a complex genetic aetiology, with RET being the major gene. This study was initiated to evaluate the RET haplotypes associated with the disease in the Chinese population. It was hypothesised that if the Hirschsprung phenotype is also related to the particular combinations of RET single nucleotide polymorphisms (SNPs), and if the incidence of those SNPs differs among populations, identification of those population specific alleles and haplotypes contributing to disease would help elucidate the molecular basis underlying Hirschsprung's disease.

- The transmission disequilibrium test (TDT) and standard case-control statistics were used for comparison of RET haplotypes. Haplotypes were also compared between patients with different Hirschsprung's disease phenotypes and RET mutation status.

- One main haplotype-allele A of c135G $>A(A 45 A)$, allele $G$ of c1296G $>A(A 432 A)$, and allele $G$ of c2307T $>G(L 769 L)$ - represented $66 \%$ of the patients with Hirschsprung's disease (A-G-G, $\chi^{2}=22.23$; $p=0.000002$ ). Allele A of c1296G $>A$ and haplotypes comprising it were associated with the more severe manifestations of the disease $(p=0.000074)$, regardless of the RET mutation status.

- The finding of A-G-G in $66 \%$ of Chinese patients with Hirschsprung's disease indicates that they share the same genetic aetiology.

- These findings are relevant to Hirschsprung's disease disease risk and to gene mapping, particularly for genome-wide linkage disequilibrium testing through the use of SNP markers.

- mutations in RET non-coding region that remain to be found;

- RET could be under epistatic regulation, and the interaction of several unlinked genes is required to produce the phenotype 232428 ;

- RET specific SNPs, or a combination of these, could act as low susceptibility alleles or as factors modifying the phenotypic expression, or even be in linkage disequilibrium with an unknown susceptibility locus. ${ }^{30-33}$

Abbreviations: HWE, Hardy-Weinberg equilibrium; LSA, long segment aganglionosis; NT, chromosomes not transmitted; SNP, single nucleotide polymorphism; SSA, short segment aganglionosis; TDT, transmission disequilibrium test; TR, chromosomes transmitted 
Genetic differences in risk factors among human populations derive mainly from gradations in allele frequencies rather than from distinctive "diagnostic" genotypes. Thus the structure of human populations is relevant in various epidemiological contexts, and to our knowledge, RET polymorphism studies have only been conducted in white populations. RET SNP profiling, together with the investigation of RET alleles that could act as susceptibility factors in our population, will help to provide a better understanding of the mechanism of Hirschsprung's disease. In this paper, we present the first study on the RET polymorphisms found in Chinese patients with Hirschsprung's disease, together with their genotype and haplotype distributions.

\section{METHODS}

\section{Patients and controls}

Eighty seven ethnic Chinese patients diagnosed with sporadic Hirschsprung's disease between January 1984 and April 2003 were included in the study. The diagnosis was based on histological examination of either biopsy or surgical resection material for the absence of enteric ganglia. Using polymerase chain reaction (PCR) amplification and direct sequencing, we screened the 21 exons of the RET gene, including intron/exon boundaries, from 87 patients, 52 available parents, and 100 ethnically matched controls. All individuals assented to the molecular analyses. The primers and PCR conditions used were as previously described. ${ }^{34}$ For exon 21 , we generated the following pair of primers: 5'-AAAGGGAGTTTTGCCAAGGCC3' (forward) and 5'-TTTAAGTCTGAAGAGCAGGC-3' (reverse), which yielded a 157 base pair (bp) product.

\section{Statistical analysis}

The allele frequencies in patients and controls were calculated from the genotype frequencies and compared by the $\chi^{2}$ test or Fisher's exact test when an expected cell value was less than 5. Haplotype frequencies were estimated, using the EM algorithm as implemented in the EH program. ${ }^{35} \mathrm{EH}$ is a linkage utility program to test and estimate linkage disequilibrium between different markers or between a disease locus and markers. To test whether haplotype frequencies were significantly different between cases and controls, we did three separate analyses using the EH program: on the case subjects alone, on the control subjects alone, and on the combination of case and controls subjects. The three

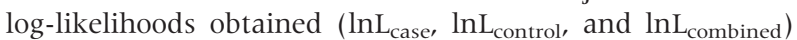
were used to calculate the relevant statistical test:
Table 1 Classification of the patients according to the length of the aganglionic segment (phenotype) and the RET mutation status

\begin{tabular}{lll}
\hline Phenotype & With mutation & Without mutation \\
\hline LSA $(n=14$ & $6(37.5 \%)$ & $8(11.3 \%)$ \\
SSA $(n=73)$ & $10(62.5 \%)$ & $63(88.7 \%)$ \\
& $(n=16)$ & $(n=71)$ \\
\hline
\end{tabular}

LSA, long segment aganglionosis; SSA, short segment aganglionosis.

$\mathrm{T}=\left[\ln \left(\mathrm{L}_{\text {case }}\right)+\ln \left(\mathrm{L}_{\text {control }}\right)-\ln \left(\mathrm{L}_{\text {combined }}\right)\right]$. Twice this value gives an approximate $\chi^{2}$ distribution with a number of degrees of freedom (df) equal to the number of haplotypes estimated under the hypothesis that allelic association is allowed. The EH program, which assumes Hardy-Weinberg equilibrium, was also used to estimate linkage disequilibrium between polymorphisms. GENEHUNTER (version 2.1) was used to undertake a transmission disequilibrium test (TDT) for marker haplotypes. Probability $(p)$ values were considered suggestive at a level of $<0.05$, and significant at a level of $<0.005$, to allow for the testing of 13 partially correlated markers.

\section{RESULTS}

\section{RET mutations and polymorphisms}

Sequencing analyses showed that 16 patients (18.4\%) had potentially disease causing mutations in the RET gene (Garcia-Barceló M-M et al, unpublished data). Classification of the patients according to the length of the aganglionic segment (phenotype) and the RET mutation status is shown in table 1.

Thirteen single nucleotide polymorphisms (SNPs) were found, of which five were new. The frequencies of these five new polymorphisms were $<5 \%$ in both patients and controls, and are likely to be private to our population, thus indicating ethnic differences in the RET-SNP profile. Except for $\mathrm{cl35G}>\mathrm{A}(\mathrm{A} 45 \mathrm{~A})$, the rest of the loci were in HardyWeinberg equilibrium (HWE) when checked for the total population; $\mathrm{Cl} 35 \mathrm{G}>\mathrm{A}(\mathrm{A} 45 \mathrm{~A})$ deviated slightly from HWE in the total population but HWE was conserved in the control population. The frequencies of the SNPs and their comparison with those reported for white subjects are shown in table $2 . .^{36}$ The alleles associated $(\mathrm{p}<0.05)$ with

Table 2 Allele frequencies of RET single nucleotide polymorphisms in 87 sporadic Chinese cases of Hirschsprung's disease and 100 ethnically matched controls

\begin{tabular}{|c|c|c|c|c|c|c|c|c|}
\hline \multirow[b]{3}{*}{ Exon } & \multirow[b]{3}{*}{ Nucleotide change } & \multirow[b]{3}{*}{ Codon } & \multirow{2}{*}{\multicolumn{2}{|c|}{$\begin{array}{l}\text { Frequency of the variant } \\
\text { allele }(\%)\end{array}$}} & \multirow{2}{*}{\multicolumn{2}{|c|}{ Statistic }} & \multicolumn{2}{|c|}{ Frequency of the variant allele $(\%)$} \\
\hline & & & & & & & \multirow{2}{*}{$\begin{array}{l}\text { Spanish }^{*} \\
\text { Controls } v \text { patients } \\
\left(\chi^{2} ; p \text { value }\right)\end{array}$} & \multirow{2}{*}{$\begin{array}{l}\text { Germant } \\
\text { Controls } v \text { patients } \\
\left(\chi^{2} ; p \text { value }\right)\end{array}$} \\
\hline & & & Controls (100) & Patients (87) & $\chi^{2}$ & p Value & & \\
\hline- & IVS1-17 T>G (new) & - & 0 & 1.1 & 1.15 & 0.28 & ND & ND \\
\hline 2 & cl29 C>G (new) & D43E & 1 & 0 & 0.87 & 0.34 & ND & ND \\
\hline 2 & $\operatorname{cl} 35 \mathrm{G}>\mathrm{A}$ & $\mathrm{A} 45 \mathrm{~A}$ & 41 & 73 & 38.62 & $<0.0001$ & 16 v $59(62.5 ;<0.0001)$ & 23 v $73.4(93.1 ;<0.001)$ \\
\hline 2 & $c 200 \mathrm{G}>\mathrm{A}$ (new) & R67H & 2.5 & 0.5 & 2.18 & 0.14 & ND & ND \\
\hline- & IVS2+9 G>A & - & 10.5 & 5.1 & 3.60 & 0.06 & ND & ND \\
\hline 3 & c375 C>A & V125V & 0.5 & 0.5 & 0.01 & 0.92 & $3 \vee 7(F ; 0.15)$ & 1.9 v $2.4(0.12 ; 0.7)$ \\
\hline 7 & cl296 G>A & A432A & 21 & 12 & 5.30 & 0.02 & $30 \vee 21.8(F ; 0.14)$ & $27.6 \vee 25.8(0.14 ; 0.7)$ \\
\hline 7 & cl465 G>A (new) & D489N & 2 & 3.4 & 0.75 & 0.39 & ND & ND \\
\hline 11 & $c 2071 \mathrm{G}>\mathrm{A}$ & G691S & 10.5 & 4.5 & 4.53 & 0.03 & $23.5 \vee 12.5(5.4 ; 0.02)$ & 20.2 v $10.5(5.8 ; 0.016)$ \\
\hline 11 & c2037 C >T (new) & P679P & 0.5 & 0.5 & 0.01 & 0.92 & ND & ND \\
\hline 13 & c2307 T>G & L769L & 49 & 75.2 & 28.05 & $<0.0001$ & 14 v $30.5(12 ;<0.0001)$ & 23.7 v $42.7(15.5 ;<0.001)$ \\
\hline 14 & c2508 C>T & S836S & 0 & 0 & - & - & 4 vs. 2.3 (F;0.54) & $3.6 \vee 0(4.8 ; 0.032)$ \\
\hline 15 & $c 2712 C>G$ & S904S & 10.5 & 4.5 & 4.53 & 0.03 & $23.5 \vee 12.5(5.4 ; 0.02)$ & $20 \vee 11.3(4.5 ; 0.03)$ \\
\hline
\end{tabular}

*Borrego et al, 1999; +Fitze et al, 1999.

F, Fisher's exact test; ND, not described; 
Table 3 Transmission disequilibrium test (TDT) by individual polymorphic locus

\begin{tabular}{llllll}
\hline & & \multicolumn{2}{l}{ TDT } & & \\
\cline { 3 - 4 } Codon & SNP (allele) & TR & NT & $\chi^{2}$ & p Value \\
\hline A45A & cl35G $>$ A (A) & 49 & 12 & 22.44 & 0.000002 \\
A432A & cl296G $>$ A (A) & 9 & 24 & 6.82 & 0.009 \\
L769L & c2307T $>$ G (G) & 53 & 15 & 21.24 & 0.000004 \\
\hline \multirow{2}{*}{ NT, chromosomes not transmitted; SNP, single nucleotide polymorphism; TR, chromosomes transmitted }
\end{tabular}

Hirschsprung's disease in our population were allele A of cl35G $>A(A 45 A)$, allele A of cl296G $>A(A 432 A)$, allele $G$ of c2307T $>$ G(L769L), allele $G$ of c2712C $>$ G(S904S), and allele $A$ of $\mathrm{c} 207 \mathrm{lG}>\mathrm{A}(\mathrm{G} 691 \mathrm{~S})$. Association of allele $\mathrm{A}$ of cl35G $>A(A 45 A)$, allele A of cl296G $>A(A 432 A)$, and allele $G$ of $c 2307 T>G($ L769L) was independently tested by TDT (table 3). The allele A of cl296G $>$ A(A432A) was significantly underrepresented in Chinese patients.

\section{RET genotype distribution}

Forty two different genotypes encompassing the 13 RET SNPs found were observed among cases and controls (not shown). The overall genotype distribution differed significantly between cases and controls $\left(\chi^{2}=79.08 ; 41 \mathrm{df}\right.$; $\mathrm{p}=0.000327)$. One to one genotype comparisons showed that four main genotypes (of 42) showed a significant difference between patients and controls (genotypes 1 to 4 in table 4). The most common disease associated RET genotype (50.6\%; genotype 1) was that homozygous for both allele A of cl35G $>A(A 45 A)$ and allele $G$ of $c 2307 T>G(L 769 L)$, and wild-type for the rest of polymorphisms found. Genotypes heterozygous for these two polymorphisms (genotypes 2 and 8 ) were instead overrepresented in the control population.

\section{Identification of the main RET haplotype in Chinese patients with Hirschsprung's disease}

We constructed the haplotypes comprising the three most significantly disease associated RET SNPs in our population $(\mathrm{cl35G}>\mathrm{A}(\mathrm{A} 45 \mathrm{~A}), \mathrm{cl} 296 \mathrm{G}>\mathrm{A}(\mathrm{A} 432 \mathrm{~A})$, and $\mathrm{c} 2307 \mathrm{~T}>\mathrm{G}(\mathrm{L} 769 \mathrm{~L}))$ and on the basis of published reports. ${ }^{36} 37$ Significant differences were observed in the global haplotype distribution between patients and controls $\left(\chi^{2}=42.46 ; \mathrm{p}<0.00001\right.$ for haplotypes; $\chi^{2}=57.52 ; \mathrm{p}<0.00001$ for genotypes). One to one comparison revealed significant differences between patients and controls for haplotypes A-G-G, G-G-T, and G-A-T. A TDT test done in 52 parent-proband trios confirmed the results (table 5). A-G-G was the most common case haplotype in our population, with an estimated frequency of $66 \%$.

\section{RET-SNPs and RET haplotypes in different Hirschsprung phenotypes}

To investigate whether RET-SNPs are associated with a particular Hirschsprung phenotype, we compared the allelic distribution of the polymorphisms described above between patients with long/total segment aganglionosis (LSA) and patients with short segment aganglionosis (SSA), and also between patients harbouring mutations in RET or not. Only allele A of cl296G $>$ A(A432A) was significantly underrepresented in SSA patients (table 6). TDT, done in 45 parent-proband trios with SSA, showed that allele G was the most frequently transmitted allele (TR:NT 22:6; $\chi^{2}=9.14$; $\mathrm{p}=0.002$ ). None of the SNPs revealed statistically significant differences in frequencies between patients with RET mutation and those without (table 6).

\section{Three-loci haplotype}

To test the previously observed association of allele A of cl296G >A(A432A) with LSA, we investigated whether the haplotype distribution differed between LSA and SSA patients. Allele A had already been found significantly underrepresented when all patients with Hirschsprung's disease were compared with controls, and from these observations a protective role for this allele seemed plausible. However, the frequency of allele " $\mathrm{A}$ " in patients affected with LSA, although not statistically significant, was higher than for the same allele in controls, which is at odds with a

Table 4 Frequency of RET genotypes in patients with Hirschsprung's disease and controls

\begin{tabular}{|c|c|c|c|c|c|c|c|c|c|c|c|c|}
\hline \multirow[b]{2}{*}{ Genotype‡§ } & \multirow{2}{*}{$\begin{array}{l}\text { A45A } \\
\text { c135 G }>\text { A }\end{array}$} & \multirow{2}{*}{$\begin{array}{l}\text { V125V } \\
\text { c } 375 \mathrm{C}>\mathrm{A}\end{array}$} & \multirow{2}{*}{$\begin{array}{l}\text { A432A } \\
\text { c1296 G }>\text { A }\end{array}$} & \multirow{2}{*}{$\begin{array}{l}\text { G691S } \\
\text { c2071 } \\
G>A\end{array}$} & \multirow{2}{*}{$\begin{array}{l}\text { L769L } \\
\text { c2307 } \\
T>G\end{array}$} & \multicolumn{2}{|c|}{$\begin{array}{l}\text { Chinese patients } \\
(n=87)\end{array}$} & \multirow{2}{*}{$\begin{array}{l}\text { Chinese } \\
\text { controls } \\
(n=100) \\
(\%)\end{array}$} & \multirow[b]{2}{*}{$\chi^{2}$} & \multirow[b]{2}{*}{ p Value } & \multirow{2}{*}{$\begin{array}{l}\text { Spanish } \\
\text { patients } \\
(n=62)^{*} \dagger \\
(\%)\end{array}$} & \multirow{2}{*}{$\begin{array}{l}\text { Spanish } \\
\text { controls } \\
(n=65) \\
(\%)\end{array}$} \\
\hline & & & & & & (n) & (\%) & & & & & \\
\hline 1 & AA & $\mathrm{CC}$ & GG & $\mathrm{CC}$ & GG & 44ף & 50.6 & 12 & 29.81 & $<0.0001$ & 4.8 (CC) & 1.5 \\
\hline 2 & GA & $\mathrm{CC}$ & GG & $\mathrm{CC}$ & TG & 5 & 5.7 & $26+†$ & 11.83 & $<0.0001$ & $3.2(\mathrm{AC})$ & 0.0 \\
\hline 3 & GG & $\mathrm{CC}$ & GA & $\mathrm{CC}$ & $\pi$ & 0 & 0.0 & 5 & 4.47 & 0.03 & 4.8 (AD) & 18.5 \\
\hline 4 & GG & $\mathrm{CC}$ & GG & $\mathrm{CC}$ & TG & 1 & 1.1 & 8 & 4.77 & 0.02 & $0.0(\mathrm{AL})$ & 1.5 \\
\hline 5 & AA & $\mathrm{CC}$ & GG & $\mathrm{CC}$ & $\pi$ & 0 & 0 & 0 & - & - & 11.3 (BB) & 0.0 \\
\hline 6 & $\mathrm{AA}$ & $\mathrm{CC}$ & GG & $\mathrm{CC}$ & TG & 3 & 3.5 & 1 & 1.33 & 0.24 & 9.7 (BC) & 3.1 \\
\hline 7 & GA & $\mathrm{CC}$ & GG & $\mathrm{CC}$ & GG & 4 & 4.6 & 2 & 1.01 & 0.31 & 0.0 (CL) & 0.0 \\
\hline 8 & GA & $\mathrm{CC}$ & GA & $\mathrm{CC}$ & TG & $3^{* *}$ & 3.5 & 9 & 2.39 & 0.12 & $11.3(\mathrm{AF} / \mathrm{CD})$ & 0.0 \\
\hline 9 & GA & CA & GG & $\mathrm{CC}$ & $\pi$ & 0 & 0 & 0 & - & - & $9.7(\mathrm{BH})$ & 0.0 \\
\hline 10 & GA & $\mathrm{CC}$ & GA & $\mathrm{CC}$ & $\mathrm{TT}$ & 0 & 0 & 2 & 1.76 & 0.18 & 6.5 (BD) & 0.0 \\
\hline 11 & GG & $\mathrm{CC}$ & GG & $\mathrm{CC}$ & $\pi$ & 5 & 5.7 & 4 & 0.31 & 0.57 & 0.0 (AA) & 12.3 \\
\hline \multicolumn{6}{|c|}{ Rest of genotypes combined } & 22 & 25.3 & 31 & 5.9 & 0.01 & 38.7 & 63.1 \\
\hline
\end{tabular}

*Borrego et al, 2000.

†Capital letters in brackets represent genotypes as designated in Borrego et al, 2000.

fOnly those genotypes with significant differences in frequencies between both populations are represented.

$\S$ In bold, genotypes with statistically significant differences between Chinese patients and controls.

-One individual was TG for IVS1-17 T>G and another individual was GA for c1465 G>A D489N.

**Two individuals were GA for IVS2+9 G>A.

††One individual was GA for IVS2+9 G>A and another individual was GA for cl 465 G>A D489N. 
Table 5 Comparison of haplotype frequencies between patients with Hirschsprung's disease and controls, and results of haplotype analysis using the transmission disequilibrium test

\begin{tabular}{|c|c|c|c|c|c|c|c|c|c|}
\hline \multirow{2}{*}{$\begin{array}{l}\text { A45A } \\
\text { c135G }>\text { A }\end{array}$} & \multirow{2}{*}{$\begin{array}{l}\text { A432A } \\
\text { c1296G }>\text { A }\end{array}$} & \multirow{2}{*}{$\begin{array}{l}\text { L769L } \\
\text { C2307T }>G\end{array}$} & \multicolumn{3}{|c|}{ Frequencies estimated by EH } & \multicolumn{4}{|c|}{ TDT } \\
\hline & & & Controls $(n=100)$ & All patients $(n=87)$ & $\mathrm{p}$ Value & TR & NT & $\chi^{2}$ & $\mathrm{p}$ Value \\
\hline A & G & G & 0.372 & 0.660 & 0.009 & 43 & 9 & 22.23 & 0.000002 \\
\hline G & A & T & 0.164 & 0.052 & 0.01 & 3 & 16 & 8.89 & 0.0028 \\
\hline G & G & T & 0.322 & 0.147 & 0.03 & 7 & 27 & 11.76 & 0.0006 \\
\hline A & A & G & 0.009 & 0.021 & $>0.05$ & 3 & 2 & 0.20 & 0.65 \\
\hline A & A & $\mathrm{T}$ & 0.004 & 0.011 & $>0.05$ & 0 & 1 & 1.00 & 0.32 \\
\hline A & G & T & 0.024 & 0.037 & $>0.05$ & 1 & 2 & 0.33 & 0.56 \\
\hline G & A & G & 0.032 & 0.036 & $>0.05$ & 4 & 4 & 0.00 & 1.00 \\
\hline G & G & G & 0.071 & 0.035 & $>0.05$ & 4 & 4 & 0.00 & 1.00 \\
\hline
\end{tabular}

EH, linkage utility program; NT, chromosomes not transmitted; TDT, transmission disequilibrium test; TR, chromosomes transmitted.

\begin{tabular}{|c|c|c|c|}
\hline \multirow[b]{2}{*}{ Codon } & \multirow[b]{2}{*}{ SNP (allele) } & \multicolumn{2}{|c|}{ Sporadic cases of Hirschsprung's disease } \\
\hline & & LSA $(n=14) \vee$ SSA $(n=73)$ & $\begin{array}{l}\text { Without mutation }(n=71) v \text { with } \\
\text { mutation }(n=16)\end{array}$ \\
\hline $\begin{array}{l}\text { A45A } \\
\text { A432A } \\
\text { L769L }\end{array}$ & $\begin{array}{l}c 135 G>A(A) \\
c 1296 G>A(A) \\
c 2307 T>G(G)\end{array}$ & $\begin{array}{l}67.8 \vee 73.9\left(\chi^{2}=0.45, p=0.50\right) \\
25 \vee 9.5\left(\chi^{2}=5.26, p=0.02\right) \\
78.5 \vee 74.6\left(\chi^{2}=0.19, p=0.66\right)\end{array}$ & $\begin{array}{l}70.4 \vee 84.3\left(\chi^{2}=2.6, p=0.10\right) \\
12.6 \vee 15.6\left(\chi^{2}=0.47, p=0.50\right) \\
87.5 \vee 64.8\left(\chi^{2}=2.9, p=0.08\right)\end{array}$ \\
\hline
\end{tabular}

protective role. This suggested that the association of allele A with LSA was in combination with other polymorphisms within RET.

Global haplotype and genotype distributions showed statistically significant differences between SSA and LSA patients $\left(\chi^{2}=20.84 ; \mathrm{p}=0.004\right.$ for haplotypes, and $\chi^{2}=35.9$; $\mathrm{p}=0.0006$ for genotypes). Haplotype A-A-G was more common in LSA patients ( $14 \% v 0 \%$ in SSA; Fisher's two tailed exact test, $\mathrm{p}=0.000075$ ) and haplotype A-G-G in SSA $\left(69.7 \% \quad v \quad 46.4 \%\right.$ in LSA; $\left.\chi^{2}=16.3 ; \mathrm{p}=0.000041\right)$. TDT confirmed the preferable transmission of the haplotype A-G-G in the SSA group (table 7).

Although parents were only available for seven LSA patients, TDT results showed a statistical trend towards the transmission of A-A-G in this group. It is likely that the TDT values did not reach statistical significance in LSA patients owing to the small sample size analysed. However, as our patients and controls are ethnically matched, there is little distortion of the data obtained by $\mathrm{EH}$, and the significance reached by case-control standard statistics accurately reflects the trends observed.

The results obtained in this three-loci haplotype analysis suggest that while both allele A of cl35G $>$ A(A45A) and allele $G$ of c2307T $>\mathrm{G}(\mathrm{L} 769 \mathrm{~L})$ are associated with Hirschsprung's disease independently of the severity of the phenotype, allele A of cl296G $>$ A(A432A) in combination with the variant alleles of $\mathrm{cl35G}>\mathrm{A}(\mathrm{A} 45 \mathrm{~A})$ and $\mathrm{c} 2307 \mathrm{~T}>$ $\mathrm{G}(\mathrm{L} 769 \mathrm{~L})$ is associated with the more severe form of Hirschsprung's disease.

\section{Two-loci haplotype}

To determine whether the association found for cl296G $>$ A(A432A) was driven by the other polymorphic alleles associated with Hirschsprung's disease, three two-loci haplotype distributions-Cl35G $>$ A (A45A)-c2307T $>$ G(L769L), $\mathrm{cl} 35 \mathrm{G}>\mathrm{A}(\mathrm{A} 45 \mathrm{~A})-\mathrm{cl} 296 \mathrm{G}>\mathrm{A}(\mathrm{A} 432 \mathrm{~A})$, and $\mathrm{cl} 296 \mathrm{G}>\mathrm{A}(\mathrm{A} 432 \mathrm{~A})-$ c2307T $>$ G(L769L) -were compared between LSA and SSA patients. As expected, for the combination cl35G> $A(A 45 A)$-c2307T $>$ G(L769L), no difference between SSA and LSA patients was found. However, significant differences in the global genotype and haplotype distributions between LSA and SSA patients were observed for the combination (cl35G $>$ A)A45A-cl296G $>$ A(A432A) $\left(\chi^{2}=19\right.$; $\mathrm{p}=0.0012$ for genotypes and $\chi^{2}=12.64 ; \mathrm{p}=0.0054$ for haplotypes), and the combination cl296G $>\mathrm{A}(\mathrm{A} 432 \mathrm{~A})$ c2307T $>$ G(L769L $)\left(\chi^{2}=18.9 ; p=0.001\right.$ for genotypes, and $\chi^{2}=13.08 ; p=0.0044$ for haplotypes). In particular, for cl35G $>A(A 45 A)-c l 296 G>A(A 432 A)$, haplotype A-G was predominant in SSA patients $(73 \% \quad v \quad 49 \%$ in LSA; $\left.\chi^{2}=12.11 ; \mathrm{p}=0.0005\right)$ and this was confirmed by TDT

Table 7 Results of haplotype analysis on LSA and SSA triads using the transmission disequilibrium test

\begin{tabular}{|c|c|c|c|c|c|c|c|c|c|c|}
\hline \multirow{2}{*}{$\begin{array}{l}\text { A45A } \\
\text { c135G }>\text { A }\end{array}$} & \multirow{2}{*}{$\begin{array}{l}\text { A432A } \\
\text { cl296G }>\text { A }\end{array}$} & \multirow{2}{*}{$\begin{array}{l}\text { L769L } \\
\text { c2307T }>G\end{array}$} & \multicolumn{4}{|c|}{ TDT (7 LSA trios) } & \multicolumn{4}{|c|}{ TDT (45 SSA trios) } \\
\hline & & & TR & NT & $\chi^{2}$ & $p$ Value & TR & NT & $\chi^{2}$ & p Value \\
\hline$A$ & $G$ & $G$ & 5 & 1 & 2.67 & 0.10 & 38 & 8 & 19.57 & 0.00001 \\
\hline$A$ & $A$ & G & 3 & 0 & 3.00 & 0.08 & 0 & 2 & 2.00 & 0.15 \\
\hline$A$ & $A$ & $T$ & 0 & 0 & - & - & 0 & 1 & 1.00 & 0.31 \\
\hline A & G & $\mathrm{T}$ & 0 & 0 & - & - & 1 & 2 & 0.33 & 0.56 \\
\hline$G$ & $A$ & G & 1 & 1 & 0.00 & 1.00 & 3 & 3 & 0.00 & 1.00 \\
\hline G & G & $G$ & 2 & 0 & 2.00 & 0.15 & 2 & 4 & 0.67 & 0.41 \\
\hline G & $A$ & $\mathrm{~T}$ & 0 & 2 & 2.00 & 0.16 & 3 & 14 & 7.12 & 0.007 \\
\hline G & G & $\mathrm{T}$ & 0 & $\overline{7}$ & 7.00 & 0.008 & 7 & 20 & 6.26 & 0.41 \\
\hline
\end{tabular}

LSA, long segment aganglionosis; NT, chromosomes not transmitted; SSA, short segment aganglionosis; TR, chromosomes transmitted. 
done in 45 SSA trios (TR:NT 38:8; $\chi^{2}=19.57 ; p=0.00001$ ). Haplotype A-A was significantly more common in LSA patients $\left(18 \% \vee 0.8 \%\right.$ in SSA; $\left.\chi^{2}=17.37 ; \mathrm{p}=0.000031\right)$.

As for pair cl296G $>A(A 432 A)-c 2307 T>G(L 769 L)$, the most dramatic difference between SSA and LSA was that of the haplotype A-G ( $1.5 \%$ in SSA $v 24 \%$ in LSA; $\chi^{2}=22.8$; $\mathrm{p}=0.000002)$. Haplotype $\mathrm{G}-\mathrm{G}$ was significantly overrepresented in the SSA group $\left(73 \% v 53 \%, \chi^{2}=8.6 ; p=0.003\right)$. TDT done in the SSA group also showed that G-G was preferably transmitted (TR:NT 38:9; $\chi^{2}=17.89 ; \mathrm{p}=0.00002$ ).

Two-loci haplotype analysis confirmed that allele A of cl296G $>A(A 432 A)$ in cis combination with either allele A of cl35G $>A(A 45 A)$ or allele $G$ of $c 2307 T>G(L 769 L)$ is associated with LSA.

Two- and three-loci haplotype distributions showed no differences between patients with RET mutation and patients without (data not shown).

\section{RET-SNPs and RET haplotypes in other populations} Except for allele A of cl296G $>$ A(A432A), those polymorphic alleles associated with Hirschsprung's disease in Chinese patients (in particular allele A of $\mathrm{cl35G}>\mathrm{A}(\mathrm{A} 45 \mathrm{~A})$ and allele $\mathrm{G}$ of $\mathrm{c} 2307 \mathrm{~T}>\mathrm{G}(\mathrm{L} 769 \mathrm{~L})$ ) are also associated with the disease in white patients. However, the RET-SNP frequencies found in our population (in both patients and controls) differ considerably from those reported for the same SNPs in white subjects (table 2). For instance, the frequency of allele A of cl35G $>A(A 45 A)$ varied greatly between Chinese and white control populations $(41 \% \vee 16-23 \%$, respectively) but remained rather similar for the two patient populations (73\% in Chinese $v$ 59-73.4\% in whites). Allele G of c2307T $>$ G(L769L) occurred much more often in Chinese patients $(75.2 \%)$ than in white patients $(30.5 \%-42.7 \%)$. In addition, while the frequencies of the variant alleles of cl35G $>A(A 45 A)$ and $c 2307 T>G(L 769 L)$ were similar in the Chinese population (patients and controls), they differed greatly in white subjects (table 2). As to the c2508C $>$ T(S836S) polymorphism, the variant allele $\mathrm{T}$ was not found either in patients or controls. In whites, c2508C $>\mathrm{T}(\mathrm{S} 836 \mathrm{~S})$ is characterised by the low frequency of the allele $\mathrm{T}$ in patients with Hirschsprung's disease and its overrepresentation in medullary thyroid carcinoma. ${ }^{33}$ 38-40

The ethnic differences observed in the SNP frequencies were reflected in the frequencies of the RET genotypes/ haplotypes associated with Hirschsprung's disease. Genotypes and haplotypes encompassing the same SNPs were compared with those previously reported in the only RET haplotype study done in white (Spanish) patients with Hirschsprung's disease (table 4). ${ }^{30}$ While $50.6 \%$ of the Chinese patients shared the same genotype-genotype 1; homozygous for both allele A of cl35G $>$ A (A45A) and allele $G$ of $c 2307 T>G(L 769 L)$ and wild-type for the rest of polymorphisms found-five different genotypes (BB, BC, $\mathrm{BD}, \mathrm{BH}$ and $\mathrm{CD}$ ) together accounted for a similar number $(48 \%)$ of Spanish patients. In addition, those four genotypes were rare in our patient population-that is, the most common Hirschsprung's disease genotype in Spanish people (BB) is not observed in the Chinese. Furthermore, the most common Hirschsprung haplotype seen in Chinese people (A-G-G; 66\%; $\quad$ cl35G $>A(A 45 A), \quad$ cl296G $>A(A 432 A)$, C2307T $>$ G(L769L); table 5) was only seen in $19 \%$ of the Spanish patients; vice versa, the most common Hirschsprung haplotype in Spaniards (30.7\%; haplotype B: allele A of of cl35G $>A(A 45 A)$ and wild-type for the other sites) was only seen in $3.7 \%$ of the Chinese patients. Genotypes and haplotypes comprising both allele A of cl35G $>A(A 45 A)$ and allele $G$ of c2307T $>G($ L769) are particularly associated with Hirschsprung's disease in Chinese people, while in whites the main genotype and haplotype associated with
Hirschsprung's disease comprise only allele A of cl35G $>$ A(A45A).

\section{DISCUSSION}

The current data on Hirschsprung's disease indicate that RET haplotypes associated with this condition can themselves be functional and lead to a low penetrance loss of function, act as modifiers of the phenotype conferring risk/protection to disease (additive/combinatorial effect of multiple RET polymorphisms, combinatory hypothesis), or represent linkage disequilibrium with a low penetrance susceptibility locus. We initiated this study to evaluate the RET "risk" haplotypes present in our population, to elucidate the molecular basis of Hirschsprung's disease. We hypothesised that if the Hirschsprung's disease phenotype is related to the particular combinations of RET-SNPs, and if the incidence of those polymorphic variants differs among populations, identification of those population specific SNPs and haplotypes contributing to disease would definitely help in the discovery of the molecular basis underlying Hirschsprung's disease.

Our data showed that Chinese patients with Hirschsprung's disease are mainly represented by one RET haplotype (comprising variant alleles of cl35G $>A(A 45 A)$ and $c 2307 \mathrm{~T}>\mathrm{G}(\mathrm{L} 769 \mathrm{~L})$ ), indicating that if this haplotype was itself functional, $66 \%$ of the Chinese patients would share the same genetic aetiology. The existing data on white patients with Hirschsprung's disease show that the haplotype distribution is more diverse and that $\mathrm{cl35G}>\mathrm{A}(\mathrm{A} 45 \mathrm{~A})$ alone is driving a strong association between haplotypes containing this polymorphism (allele A) and Hirschsprung's disease. Those differences between populations in the frequencies of the RET haplotypes with the best evidence for an association with Hirschsprung's disease suggest that the true RET disease susceptibility allele remains to be identified; alternatively they might suggest that different haplotypes in different populations confer risk of or protection against disease, and those "functional haplotypes" would also account for the patients with Hirschsprung's disease with no mutations in any of the Hirschsprung genes.

In favour of the first explanation, it has been suggested recently that in Spaniards, ${ }^{31} R E T$ "risk" haplotypes appeared to be in linkage disequilibrium with a putative founding low penetrance susceptibility locus, located upstream of cl35G $>A(A 45 A)$. Thus it could be that the "true" susceptibility locus" is on different haplotype backgrounds because of human population and history and structure, explaining the differences found in the RET haplotypes associated with Hirschsprung's disease. The main RET haplotype associated with Hirschsprung's disease in Chinese people still belongs to the group of haplotypes in linkage disequilibrium with the low penetrance susceptibility locus upstream of A45A, as previously described in whites. ${ }^{31}$ The differences in "risk haplotype" frequencies between Chinese and whites could indicate that recombination events within the region flanked by A45A and L769L may have occurred (after the EuropeanAsian split). This may have originated in two "risk haplotypes," one mainly represented by allele A of A45A, more common in Europeans, and another, more common in the Chinese, represented by the variants alleles of A45A and L769L. Both haplotypes could be in linkage disequilibrium with the low susceptibility locus upstream A45A previously described. ${ }^{31}$

The second explanation is not mutually exclusive with the presence of a putative locus in linkage disequilibrium with $R E T$ "risk" haplotypes, because particular combinations of SNPs on those haplotypes could also act as modifiers. ${ }^{30} 40$

We also found that allele and haplotype distributions varied with the severity of the Hirschsprung phenotype: allele A of $\mathrm{cl} 296 \mathrm{G}>\mathrm{A}(\mathrm{A} 432)$ in combination with the variant 
alleles of $\mathrm{cl} 35 \mathrm{G}>\mathrm{A}(\mathrm{A} 45 \mathrm{~A})$ and $\mathrm{c} 2307 \mathrm{~T}>\mathrm{G}(\mathrm{L} 769 \mathrm{~L})$ was associated with the more severe form of Hirschsprung's disease, while both c135G $>$ A(A45A) and c2307T $>$ G(L769L) polymorphisms were associated with Hirschsprung's disease independently of the severity of the phenotype. However, these data should be viewed with caution until further proof is provided by functional analysis.

Differences in allele frequencies between different Hirschsprung phenotypes have never been reported for cl296G $>A(A 432 A)$. Instead, in a study of 76 white patients from Germany, ${ }^{32}$ differences in the frequency of allele $\mathrm{A}$ of $\mathrm{cl} 35 \mathrm{G}>\mathrm{A}(\mathrm{A} 45 \mathrm{~A})$ were found between SSA and LSA patients, and also between patients with the RET mutation and those without. It was also shown that $\mathrm{cl35G}>\mathrm{A}(\mathrm{A} 45 \mathrm{~A})$ polymorphism can modify the phenotype through a within-gene interaction. In our series cl35G $>$ A(A45A) was not associated with any Hirschsprung phenotype or with RET mutations. Instead, cl296G $>\mathrm{A}(\mathrm{A} 432 \mathrm{~A})$ and haplotypes comprising it were associated with the more severe form of the disease. No differences were found in allele and haplotype distributions when patients harbouring or not harbouring the RET mutation were compared, which could indicate that $R E T$ specific haplotypes may influence the Hirschsprung's disease phenotype regardless of the RET mutation status. This influence could be through interaction of the RET-SNPS within RET itself or with other genes.

RET haplotypes containing the allele $\mathrm{T}$ of c2508C $>$ $\mathrm{T}$ (S836S) have a protective role in the pathogenesis of Hirschsprung's disease. ${ }^{33} 40$ This allele has not been found in the Chinese, so there is ethnic variation in the polymorphisms implicated in the phenotype modulation of Hirschsprung's disease and possibly medullary thyroid carcinoma. Interestingly, differences in the distribution of the RET haplotypes have also been detected among patients with papillary thyroid carcinoma from different white populations. ${ }^{41}$

Transmission of mutations in other Hirschsprung genes (EDRNB, GDNF) has been found to be associated with the transmission of RET polymorphisms, proving the genetic interaction underlying Hirschsprung's disease. ${ }^{24}$ Combinations of variants in several components of the RET and EDRNB signalling pathways might overall provide an important risk factor for disease susceptibility and also contribute to the necessary response to produce the Hirschsprung phenotype. When a candidate gene contains various polymorphisms, these are usually in linkage disequilibrium because the relatively small genetic distances make it difficult in a single population to dissect out the important polymorphism. Ethnic differences in the haplotypes associated with disease can make it easier to isolate the SNP that actually confers susceptibility to a given disease at a given locus. Thus our data are highly relevant to Hirschsprung's disease risk and to gene mapping, particularly for genome-wide testing for linkage disequilibrium through the use of SNP markers.

\section{ACKNOWLEDGEMENTS}

We extend our gratitude to all subjects who participated in the ?study. We thank Professor Pak Sham for critical review of the manuscript and helpful discussions. This work was supported by research grants from the Hong Kong Research Grants Council (HKU 7358/00M).

\footnotetext{
Authors' affiliations

M-M Garcia-Barceló, V C-H Lui, B L-S Chen, W-S Lee, S-K Yung, P K-H

Tam, Division of Paediatric Surgery, Department of Surgery, University of Hong Kong Medical Centre, Queen Mary Hospital, Hong Kong SAR, China

M-H Sham, Y-Q Song, Department of Biochemistry, The University of Hong Kong
}

G Romeo, Laboratory of Medical Genetics, University of Bologna, Bologna, Italy

Correspondence to: Professor Paul K-H Tam, Division of Paediatric Surgery, Department of Surgery, University of Hong Kong Medical Centre; Queen Mary Hospital, Hong Kong SAR, PR China; paultam@hkucc.hku.hk

\section{REFERENCES}

1 Chakravarti A, Lyonnet S, In: Scriver CR, Sly WS, Valle D, Beaudet AL, eds. The metabolic and molecular basis of inherited diseases, 8th ed, chapter 251. New York: McGraw-Hill, 2001.

2 Amiel J, Lyonnet S. Hirschsprung disease, associated syndromes, and genetics: a review. J Med Gen 2001;38:729-39.

3 Angrist M, Kauffman E, Slaugenhaupt SA, Matise TC, Puffenberger EG, Washington SS, Lipson A, Cass DT, Reyna T, Weeks DE, Sieber W, Chakravarti A. A gene for Hirschsprung disease (megacolon) in the pericentromeric region of human chromosome 10. Nat Genet 1993;3:351-6.

4 Lyonnet S, Bolino A, Pelet A, Abel L, Nihoul-Fekete C, Briard ML, Mok-Siu V, Kaariainen H, Martucciello G, Lerone M, Puliti A, Yin L, Weissenbach J, Devoto M, Munnich A, Romeo G. A gene for Hirschsprung disease maps to the proximal long arm of chromosome 10. Nat Genet 1993;4:346-50.

5 Edery P, Lyonnet S, Mulligan LM, Pelet A, Dow E, Abel L, Holder S, NihoulFekete C, Ponder BA, Munnich A. Mutations of the RET proto-oncogene in Hirschsprung's disease. Nature 1994;367:378-80.

6 Romeo G, Ronchetto P, Luo Y, Barone V, Seri M, Ceccherini I, Pasini B, Bocciardi R, Lerone M, Kaariainen H, Martucciello G. Point mutations affecting the tyrosine kinase domain of the RET proto-oncogene in Hirschsprung's disease. Nature 1994:367:377-8.

7 Attie T, Pelet A, Edery P, Eng C, Mulligan LM, Amiel J, Boutrand L, Beldjord C, Nihoul-Fekete C, Munnich A, Ponder BAJ, Lyonnet S. Diversity of RET protooncogene mutations in familial and sporadic Hirschsprung disease. Hum Mol Genet 1995:4:1381-6.

8 Angrist M, Bolk S, Thiel B, Puffenberger EG, Hofstra RM, Buys CH, Cass DT, Chakravarti A. Mutation analysis of the RET receptor tyrosine kinase in Hirschsprung disease. Hum Mol Genet 1995;4:821-30.

9 Seri M, Yin L, Barone V, Bolino A, Celli I, Bocciardi R, Pasini B, Ceccherini I, Lerone M, Kristoffersson U, Larsson LT, Casasa JM, Cass DT, Abramowicz MJ, Vanderwinden JM, Kravcenkiene I, Baric I, Silengo M, Martucciello G, Romeo G. Frequency of RET mutations in long- and short-segment Hirschsprung disease. Hum Mutat 1997:9:243-9.

10 Svensson PJ, Molander ML, Eng C, Anvret M, Nordenskjold A. Low frequency of RET mutations in Hirschsprung disease in Sweden. Clin Genet 1998;54:39-44.

11 Sancandi $M$, Ceccherini I, Costa M, Fava M, Chen B, Wu Y, Hofstra R, Laurie T, Griffths $M$, Burge D, Tam PK. Incidence of RET mutations in patients with Hirschsprung's disease. Pediatr Surg 2000;35:139-42.

12 Iwashita T, Kurokawa K, Qiao S, Murakami H, Asai N, Kawai K, Hashimoto M, Watanabe T, Ichihara M, Takahashi M. Functional analysis of RET with Hirschsprung mutations affecting its kinase domain. Gastroenterology 2001;121:24-33.

13 Cosma MP, Cardone M, Carlomagno F, Colantuoni V. Mutations in the extracellular domain cause RET loss of function by a dominant negative mechanism. Mol Cell Biol 1998:18:3321-9.

14 Pelet A, Geneste O, Edery P, Pasini A, Chappuis S, Atti T, Munnich A, Lenoir G, Lyonnet S, Billaud M. Various mechanisms cause RET-mediated signaling defects in Hirschsprung's disease. J Clin Invest 1998;101:1415-23.

15 Borrello MG, Smith DP, Pasini B, Bongarzone I, Greco A, Lorenzo MJ Arighi E, Miranda C, Eng C, Alberti L. RET activation by germline MEN2A and MEN2B mutations. Oncogene 1995;11:2419-27.

16 Eng C, Mulligan LM, Smith DP, Healey CS, Frilling A, Rave F, Neumann HP, Pfragner R, Behmel A, Lorenzo MJ. Mutation of the RET protooncogene in sporadic medullary thyroid carcinoma. Genes Chromosomes Cancer 1995; 12:209-12.

17 Tallini G, Asa SL. RET oncogene activation in papillary thyroid carcinoma. Adv Anat Pathol $2001 ; 8: 345-54$.

18 Puffenberger EG, Kauffman ER, Bolk S, Matise TC, Washington SS, Angrist M, Weissenbach J, Garver KL, Mascari M, Ladda R, Slaugenhaupt SA, Chakravarti A. Identity-by-descent and association mapping of a recessive gene for Hirschsprung disease on human chromosome 13q22. Hum Mol Genet 1994;3:1217-25.

19 Puffenberger EG, Hosoda K, Washington SS, Nakao K, deWit D, Yanagisawa M, Chakravarti A. A missense mutation of the endothelin-B receptor gene in multigenic Hirschsprung's disease. Cell 1994:79:1257-66.

20 Bidaud C, Salomon R, Van Camp G, Pelet A, Attie T, Eng C, Bonduelle M, Amiel J, Nihoul-Fekete C, Willems PJ, Munnich A, Lyonnet S. Endothelin-3 gene mutations in isolated and syndromic Hirschsprung disease. Eur J Hum Genet 1997:5:247-51.

21 Angrist M, Bolk S, Halushka M, Lapchak PA, Chakravarti A. Germline mutations in glial cell line-derived neurotrophic factor GDNF and RET in a Hirschsprung disease patient. Nat Genet 1996;14:341-4.

22 Hofstra RMW, Valdenaire $\mathrm{O}$, Arch E, Osinga J, Kroes H, Loffler BM, Hamosh A, Meijers C, Buys CH. A loss-of-function mutation in the endothelinconverting enzyme 1 ECE-1 associated with Hirschsprung disease, cardiac defects, and autonomic dysfunction. Am J Hum Genet 1999;64:304-8.

23 Chakravarti A. Endothelin receptor-mediated signaling in Hirschsprung disease. Hum Mol Genet 1996:5:303-7. 
24 Carrasquillo Carrasquillo MM, McCallion AS, Puffenberger EG Kashuk CS Nouri N, Chakravarti A. Genome-wide association study and mouse model identify interaction between RET and EDNRB pathways in Hirschsprung disease. Nat Genet 2002;32:237-44.

25 Pingault V, Bondurand N, Kuhlbrodt K, Goerich DE, Prehu MO, Puliti A Herbarth B, Hermans-Borgmeyer I, Legius E, Matthijs G, Amiel J, Lyonnet S, Ceccherini I, Romeo G, Smith JC, Read AP, Wegner M, Goossens M. SOX10 mutations in patients with Waardenburg-Hirschsprung disease. Nat Genet 1998;18:171-3.

26 Herbarth B, Pingault V, Bondurand N, Kuhlbrodt K, Hermans-Borgmeyer I, Puliti A, Lemort N, Goossens M, Wegner M. Mutation of the Sry-related Sox 10 gene in Dominant megacolon, a mouse model for human Hirschsprung disease. Proc Natl Acad Sci USA 1998;95:5161-5.

27 Wakamatsu N, Yamada Y, Yamada K, Ono T, Nomura N, Taniguchi H, Kitoh H, Mutoh N, Yamanaka T, Mushiake K, Kato K, Sonta S, Nagaya M. Mutations in SIP1, encoding Smad interacting protein-1, cause a form of Hirschsprung disease. Nat Genet 2001;27:369-70.

28 Bolk S, Pelet A, Hofstra RMW, Angrist M, Salomon R, Croaker D, Buys CH Lyonnet S, Chakravarti A. A human model for multigenic inheritance: phenotypic expression in Hirschsprung disease requires both the RET gene and a new 9q31 locus. Proc Natl Acad Sci USA 2000;97:268-73.

29 Gabriel Gabriel SB, Salomon R, Pelet A, Angrist M, Amiel J, Fornage M, Attie-Bitach T, Olson JM, Hofstra R, Buys C, Steffann J, Munnich A, Lyonnet S, Chakravarti A. Segregation at three loci explains familial and population risk in Hirschsprung disease. Nat Genet 2002;31:89-93.

30 Borrego S, Ruiz A, Saez ME, Gimm O, Gao X, Lopez-Alonso M, Hernandez A, Wright FA, Antinolo G, Eng C. RET genotypes comprising specific haplotypes of polymorphic variants predispose to isolated Hirschsprung disease. J Med Genet 2000;37:572-8.

31 Borrego S, Wright FA, Fernandez RM, Williams N, Lopez-Alonso M, Davuluri R, Antinolo G, Eng C. A Founding locus within the RET Protooncogene may account for a large proportion of apparently sporadic Hirschsprung Disease and a subset of cases of sporadic Medullary Thyroid Carcinoma. Am J Hum Genet 2003;72:88-100.

32 Fitze G, Cramer J, Ziegler A, Schierz M, Schreiber M, Kuhlisch E, Roesner D, Schackert HK. Association between c135G/A genotype and RET proto-oncogene germline mutations and phenotype of Hirschsprung's disease. Lancet 2002;359:1200-5.

33 Griseri P, Sancandi M, Patrone G, Bocciardi R, Hofstra R, Ravazzolo R, Devoto M, Romeo G, Ceccherini I. A single-nucleotide polymorphic variant of the RET proto-oncogene is underrepresented in sporadic Hirschsprung disease. Eur J Hum Genet 2000;8:721-4.

34 Ceccherini I, Hofstra RM, Luo Y, Stulp RP, Barone V, Stelwagen T, Bocciardi R, Nijveen H, Bolino A, Seri M, Roncheto P, Pasini B, Bozzano M, Buys C, Romeo G. DNA polymorphisms and conditions for SSCP analysis of the 20 exons of the RET proto-oncogene. Oncogene 1994:9:3025-9.

35 Zhao JH, Curtis D, Sham PC. Model-free analysis and permutation tests for allelic associations. Hum Hered 2000;50:133-9.

36 Borrego S, Saez ME, Ruiz A, Gimm O, Lopez-Alonso M, Antinolo G, Eng C. Specific polymorphisms in the RET proto-oncogene are over-represented in patients with Hirschsprung disease and may represent loci modifying phenotypic expression. J Med Genet 1999;36:771-4.

37 Fitze G, Schreiber M, Kuhlisch E, Schackert HK, Roesner D. Association of RET protooncogene codon 45 polymorphism with Hirschsprung's disease. Am J Hum Genet 1999:65:1469-73.

38 Gimm O, Neuberg DS, Marsh DJ, Dahia PL, Hoang-Vu C, Rave F, Hinze R, Dralle $H$, Eng C. Over-representation of a germline RET sequence variant in patients with sporadic medullary thyroid carcinoma and somatic RET codon 918 mutation. Oncogene 1999;18:1369-73.

39 Ruiz A, Antinolo G, Fernandez RM, Eng C, Marcos I, Borrego S. Germline sequence variant S836S in the RET proto-oncogene is associated with low level predisposition to sporadic medullary thyroid carcinoma in the Spanish population. Clin Endocrinol 2001;55:399-402.

40 Griseri P, Pesce B, Patrone G, Osinga J, Puppo F, Sancandi M, Hofstra R Romeo G, Ravazzolo R, Devoto M, Ceccherini I. A rare haplotype of the RET proto-oncogene is a risk-modifying allele in Hirschsprung disease. Am J Hum Genet 2002;71:969-74

41 Lesueur F, Corbex M, McKay JD, Lima J Soares P Griseri P, Burgess J, Ceccherini I, Landolfi S, Papotti M, Amorim A, Goldgar DE, Romeo G. Specific haplotypes of the RET proto-oncogene are over-represented in patients with sporadic papillary thyroid carcinoma. J Med Genet 2002;39:260-5 